\title{
PANORAMA ATUAL DO BRASIL \\ METROPOLITANO: O ACOMPANHAMENTO \\ DOS ARRANJOS ESPACIAIS \\ INSTITUCIONALIZADOS DO PROJETO \\ GOVERNANÇA METROPOLITANA NO BRASIL ${ }^{1}$
}

\author{
Marco Aurélio Costa ${ }^{2}$ \\ Sara Rebello Tavares ${ }^{3}$
}

\section{INTRODUÇÃO}

Desde a estruturação da Rede Ipea, uma plataforma de pesquisa em rede, por meio de um edital lançado pelo Ipea em 2011, o projeto Governança Metropolitana no Brasil vem promovendo o acompanhamento do quadro dos arranjos espaciais institucionalizados do país, envolvendo as regiōes integradas de desenvolvimento (Rides), as regiôes metropolitanas (RMs) e as aglomeraçōes urbanas (AUs).

As Rides são regiôes instituídas por meio de legislação federal complementar por envolverem municípios de mais de uma Unidade da Federação (UF). Já as RMs e as AUs agregam municípios de uma mesma UF e são criadas por meio de legislação complementar estadual.

O acompanhamento dos arranjos espaciais institucionalizados exige, portanto, a consulta, a leitura e a análise da produção legislativa de todos os 26 estados brasileiros, por meio do acesso a diferentes sites e plataformas que permitem acesso aos diários oficiais estaduais.

As informaçôes sistematizadas periodicamente pelo projeto são disponibilizadas para consulta pública na plataforma Brasil Metropolitano. ${ }^{4}$ Nela, pode-se acessar o banco de dados socioeconômicos das RMs, bem como as informaçóes jurídico-institucionais relativas às movimentações de inclusão e exclusão de municípios nessas RMs.

1. DOI: http://dx.doi.org/10.38116/brua24art15

2. Técnico de planejamento e pesquisa e coordenador de Estudos em Desenvolvimento Urbano na Diretoria de Estudos e Políticas Regionais, Urbanas e Ambientais (Dirur) do Ipea; coordenador nacional do Instituto Nacional de Ciência e Tecnologia em Políticas Públicas e Desenvolvimento Territorial (INPuT); e doutor em planejamento urbano e regional. E-mail:<marco.costa@ipea.gov.br>. 3. Pesquisadora do Programa de Pesquisa para o Desenvolvimento Nacional (PNPD) na Coordenação de Estudos em Desenvolvimento Urbano da Dirur/lpea. E-mail: <sara.tavares@ipea.gov.br>.

4. Disponível em: <www.brasilmetropolitano.ipea.gov.br>. 


\section{AS RECENTES ALTERAÇÕES NO QUADRO METROPOLITANO BRASILEIRO E O ACOMPANHAMENTO FEITO PELO PROJETO GOVERNANÇA METROPOLITANA NO BRASIL}

Em agosto de 2020, o projeto disponibilizou uma nova atualização do panorama metropolitano brasileiro, tendo como data de referência 20 de julho de 2020 .

As RMs e as AUs são instituídas com o objetivo de integrar a organização, o planejamento e a execução de funçóes públicas de interesse comum (FPICs), sendo, segundo estabelece o $\$ 3^{\circ}$ do art. 25 da Constituição Federal de 1988 (CF/1988), ${ }^{5}$ uma competência dos estados.

As Rides, por seu turno, são definidas como regióes administrativas que abrangem diferentes UFs. São criadas por legislação específica que elenca os municípios que as compóem, na qual se definem a estrutura de funcionamento e os interesses das unidades político-administrativas participantes. A competência de criar as Rides é da União, segundo o $\$ 11^{\circ}$ do art. 43 da CF/1988.

No que diz respeito à revisão atual, com data de referência de 20 de julho de 2020, náo houve alteraçôes no número de arranjos espaciais institucionalizados, permanecendo os quantitativos de 76 RMs, 3 Rides e 5 AUs.

A principal alteração observada no período foi a aprovação da Lei Complementar no 426, de 3 de abril de 2020, que dispóe sobre a RM do Recife (RMR), a qual realocou o município de Goiana na zona da mata norte. Tais movimentos de entrada e saída de municípios de arranjos institucionais são monitorados e registrados em todas as revisôes do quadro metropolitano realizadas no âmbito do projeto.

Vale destacar que, além do Ipea, existem dois órgãos que acompanham e revisam o universo metropolitano no Brasil. O primeiro é o Instituto Brasileiro de Geografia e Estatística (IBGE), que faz a revisão semestralmente. Segundo o IBGE, a finalidade principal é a identificação das unidades político-administrativas do Brasil localizadas em RMs, AUs e Rides, as quais se habilitam a um tratamento específico em função de suas particularidades de planejamento e gestáo.

A última edição disponibilizada pelo IBGE, ${ }^{6}$ no segundo semestre de 2019, não indicou alteraçôes nas unidades territoriais. Segundo o instituto, havia 74 RMs no Brasil.

A outra entidade que faz o monitoramento do quadro metropolitano é o Fórum Nacional de Entidades Metropolitanas (FNEM), uma associação civil que congrega entidades e órgãos públicos estaduais responsáveis por temas relacionados às RMs brasileiras. O FNEM, assim como o IBGE, também registrou um total de 74 RMs institucionalizadas no país.

Os números discrepantes entre Ipea, IBGE e FNEM decorrem do fato de o Ipea incluir em sua contagem duas RMs do estado do Maranhão, a saber: a RM de Grande Pedreiras (Lei Complementar Estadual no 26/1995) e a RM do Leste do Estado do Maranhão (Lei Complementar Estadual no 180/2016), ambas em vigor. A metodologia de acompanhamento do quadro metropolitano brasileiro utilizada pelo Ipea se dá, como dito anteriormente, por

5. Disponível em: <https://bit.ly/3viS6W0>.

6. A edição do segundo semestre de 2019 não apontou alterações no número de arranjos que compõem o universo metropolitano; com relação aos municípios, porém, apresentou a inclusão de novos, como o de Petrópolis, da região serrana fluminense, que voltou a integrar a RM do Rio de Janeiro, de acordo com a Lei Complementar no 184/2018. Além disso, 0 estado de Alagoas (Nordeste), com a Lei Complementar no 49/2019, incluiu o município de Atalaia à RM do Vale do Paraíba e os municípios de Igaci, Palmeira dos Índios, Estrela de Alagoas, Belém e Tanque d'Arca à RM do Agreste, totalizando dezoito municípios. Na RM alagoana de Caetés, as leis complementares nos 48 e 49, de 2019, alteraram a composição da RM, integrando a ela os municípios de Coruripe e São Miguel dos Campos. Disponível em: <https://bit.ly/2Suyuj4>. 
meio do levantamento, da leitura e da sistematização das legislaçôes estaduais, acessando a publicação da produção legislativa nos 26 estados brasileiros. Esse trabalho permite o acompanhamento não apenas do surgimento de novas unidades territoriais como também das legislaçôes que versam sobre a estrutura institucional, FPICs indicadas para a gestão e o movimento de entrada e saída dos municípios nas RMs.

A atividade periódica permite, também, identificar conflitos e incongruências no diverso universo metropolitano brasileiro. A título de exemplo, podemos citar a Lei Complementar Estadual do Alagoas no 40, de 17 de junho de 2014, que incluiu o município de Murici na RM de Maceió, embora o mesmo município já integre a RM da Zona da Mata desde 2011, conforme estabelece a Lei Complementar Estadual no 31, de 15 de dezembro de 2011, sendo que, ao longo desse período, não houve nenhuma legislação referente à saída de Murici da RM da Zona da Mata.

Algo parecido acontece com o município de Timon, que compóe a RM do Leste do Maranhão e também integra a Ride de Teresina-Timon. Nesse caso, não existe nenhuma lei que determine que um município não possa fazer parte desses tipos de arranjos institucionais, os quais envolvem diferentes estruturas de gestão. Contudo, isso demanda uma dupla convergência de diretrizes para fins de planejamento territorial, envolvendo a inserção na RM e na Ride.

O universo metropolitano atual (20 de julho de 2020) está composto, como foi dito anteriormente, por 76 RMs, 3 Rides e 5 AUs. Na somatória dos municípios, o universo é composto por 1.076 municípios metropolitanos, além de outros 232 tipificados como colar, entorno ou área de expansão metropolitana, totalizando 1.308 municípios, ou seja, quase um quarto dos municípios brasileiros. Há, ainda, 56 municípios que compóem as Rides e 74 que integram as AUs. Assim, 1.438 municípios brasileiros estão inseridos em algum arranjo espacial institucionalizado, conforme ilustra a figura 1.

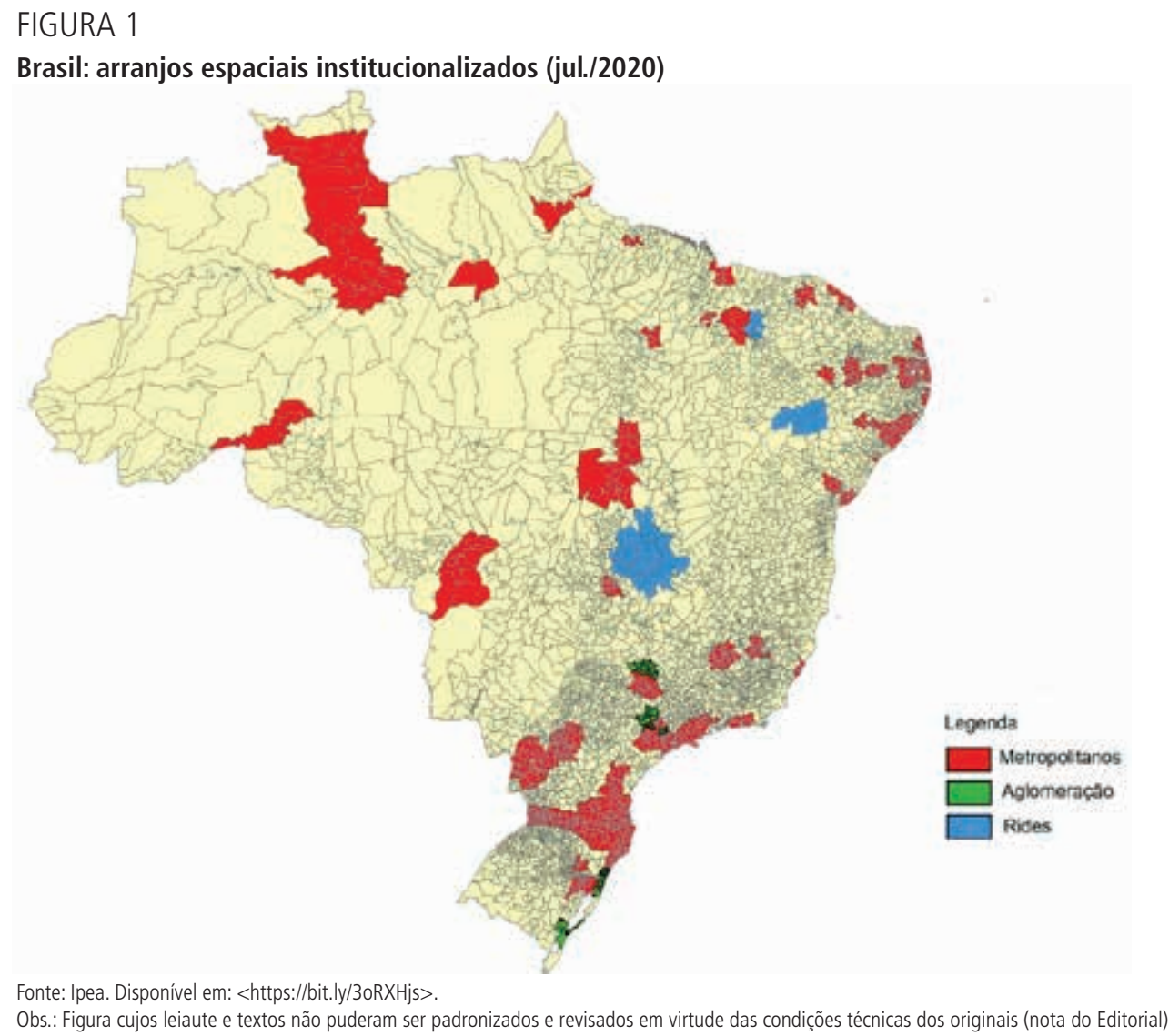


A distribuição regional do universo mostra que a região Nordeste possui o maior número de arranjos (33), enquanto a regiáo Sul abriga a maior quantidade de municípios (536). O estado com maior número de RMs é a Paraíba (12), seguido por Santa Catarina (11), Alagoas (9) e Paraná (8). Santa Catarina possui a menor e a maior RM no que concerne ao número de municípios - enquanto a RM do Norte-Nordeste Catarinense possui 5 municípios, a RM de Contestado possui 45.

TABELA 1

Brasil: distribuição dos arranjos territoriais e municípios por Grande Região (jul./2020)

\begin{tabular}{lcccccc}
\hline & RMs & Municípios RMs & Rides & Municípios Rides & AUs & Municípios AUs \\
\hline Norte & 10 & 73 & - & - & - \\
Nordeste & 33 & 391 & 2 & 22 & - & - \\
Centro-Oeste & 2 & 34 & 1 & 34 & - & - \\
Sudeste & 10 & 274 & - & - & 3 & $\mathbf{2}$ \\
Sul & 21 & 536 & $\mathbf{3}$ & $\mathbf{5 6}$ & $\mathbf{5}$ & $\mathbf{5}$ \\
Total & $\mathbf{7 6}$ & $\mathbf{1 . 3 0 8}$ & & & $\mathbf{7 4}$ \\
\hline
\end{tabular}

Fonte: Ipea, 2020.

FIGURA 2

Brasil: arranjos espaciais institucionalizados por macrorregião (jul./2020)

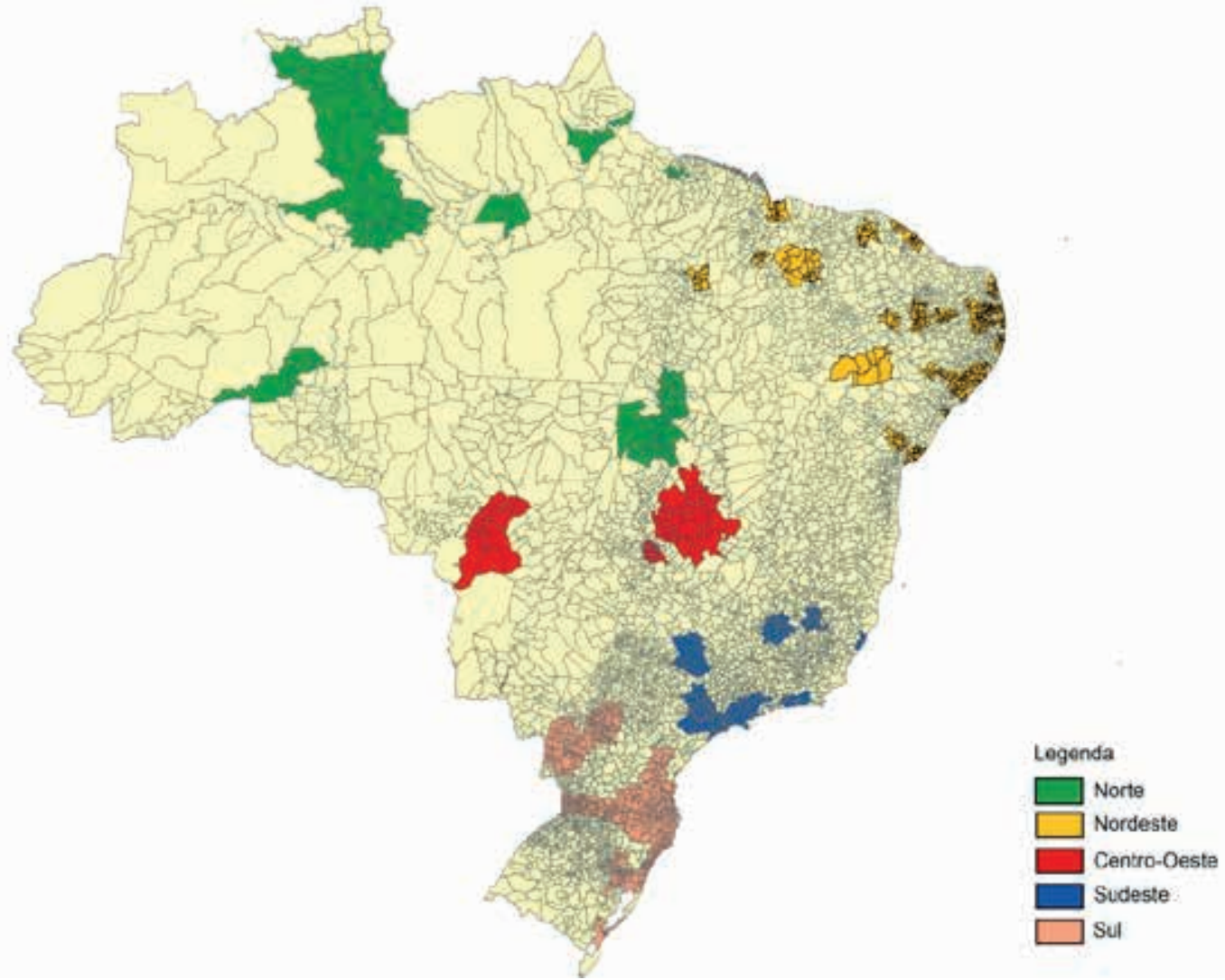

Fonte: Ipea. Disponivel em: <https://bit.ly/3oRXHjs>.

Obs.: Figura cujos leiaute e textos não puderam ser padronizados e revisados em virtude das condições técnicas dos originais (nota do Editorial).

Segundo dados disponíveis na plataforma Brasil Metropolitano, os 1.438 municípios que fazem parte dos arranjos institucionais abrigam $58 \%$ da população brasileira, o que corresponde à população estimada de 121 milhôes de pessoas, em 2018, segundo cálculos 
do IBGE. ${ }^{7}$ A RM Central (Roraima) constituía a RM de menor população, com apenas 33 mil habitantes, em contraste com a RM de São Paulo, com seus 21 milhôes.

\section{A PESQUISA REGIÃO DE INFLUÊNCIA DAS CIDADES 2018}

Além de acompanhar o quadro metropolitano brasileiro, o projeto Governança Metropolitana no Brasil tem feito comparaçóes entre o quadro institucional, decorrente da produção jurídico-administrativa dos estados brasileiros, e os estudos que procuram caracterizar o fenômeno metropolitano do ponto de vista de sua formação socioespacial.

Para acompanhar o processo socioespacial, o projeto utiliza a pesquisa Regiáo de Influência das Cidades, do IBGE, ${ }^{8}$ que traz um quadro de referência para compreender a rede urbana brasileira e, em particular, a caracterização do que seriam, efetivamente, as metrópoles brasileiras.

Na pesquisa publicada em 2020, o IBGE reconhece:

- 15 metrópoles no país, classificadas como grande metrópole nacional - a única metrópole dessa categoria corresponde ao arranjo populacional (AP) de São Paulo, com 37 municípios, dois a menos que a RM de São Paulo; e

- as metrópoles nacionais, que são duas, a saber: o AP do Rio de Janeiro (com 21 municípios, o mesmo número de municípios da RM) e o AP de Brasília (com 9 municípios, bem menos que aqueles 34 que compóem a Ride do Distrito Federal).

\section{A FASE ATUAL DO PROJETO E SUA ARTICULAÇÃO COM A POLÍTICA NACIONAL DE DESENVOLVIMENTO URBANO (PNDU)}

$\mathrm{Na}$ fase atual da pesquisa, foram produzidos 27 relatórios por parte dos quatorze arranjos que estáo inseridos no projeto. São três os componentes de pesquisa desta fase do projeto: i) um balanço das relações interfederativas estabelecidas no contexto metropolitano; ii) o acompanhamento do processo de implementação do Estatuto da Metrópole, especialmente por meio de seu principal instrumento, o Plano de Desenvolvimento Urbano Integrado (PDUI); e iii) o desafio da questão do financiamento do desenvolvimento urbano-metropolitano.

O material produzido pela pesquisa - que inclui, além dos relatórios, a publicação do quinto livro proveniente do projeto Governança Metropolitana no Brasil - está sendo utilizado para subsidiar o processo de construção da PNDU, fruto de uma importante parceria firmada entre o Ministério de Desenvolvimento Regional (MDR) e o Ipea. O quinto livro da série será publicado com apoio do MDR, no âmbito do Termo de Execução Descentralizada no 71/2019, estando seu lançamento previsto para o segundo semestre de 2021.

Informaçôes sobre o processo de implementação do Estatuto da Metrópole nas RMs brasileiras, as articulaçóes interfederativas e as experiências voltadas para viabilizar o financiamento urbano-metropolitano estão sendo sistematizadas pela equipe e estarão, em breve, disponibilizadas para o público interessado.

7. Segundo o IBGE, as estimativas das populações residentes nos 5.570 municípios brasileiros, com data de referência em 1 - de julho de 2018, foram de 208,5 milhões de habitantes, a uma taxa de crescimento populacional de 0,82\% entre 2017 e 2018, de acordo com a projeção da população (revisão 2018).

8. Disponivel em: <https://bit.ly/2RMJKHE >. 
